News \& Update

\title{
December 31 Deadline for Inaugural Diversity Award Nominations
}

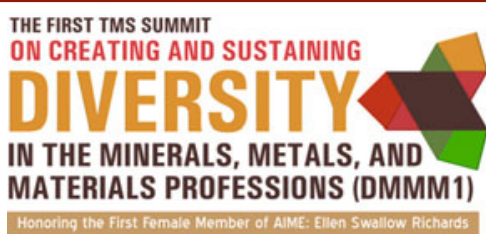

Call for Nominations Issued for Inaugural TMS Diversity Award

The Ellen Swallow Richards Diversity Award, established by the TMS Board at its September meeting, honors the legacy of the first U.S. professional degreed female scientist and the first female member of TMS's antecedent organization, the American Institute of Mining, Metallurgical, and Petroleum Engineers (AIME). The award recognizes an individual who reflects Richards's pioneering spirit in overcoming personal, professional, educational, cultural, or institutional adversity to pursue a career in minerals, metals, and/or materials or in helping others to overcome such challenges to pursue such a career.

The inaugural award will be presented at the first Summit on Creating and Sustaining Diversity in the Minerals, Metals, and Materials Professions (DMMM1): Honoring the First Female Member of AIME: Ellen Swallow Richards. The summit will be held July 29-31, 2014 at the National Academy of Sciences Building in Washington, D.C. TMS is coordinating the efforts of several associations within the science and engineering community to organize this event.

Nominations for the inaugural award are being accepted through December 31, 2013. Nominations should include the nominator's letter of support, nominee's curriculum vitae of no more than five pages, and two to five letters of recommendation. Send nomination files to Deborah Price, TMS Awards and Recognition Specialist, at price@tms.org.

This award is made possible through a generous donation to the
TMS Foundation by Jeffrey Wadsworth and his wife, Geraldine McCulley Wadsworth.

Born in 1842, Ellen Swallow Richards was a member of Vassar College's first graduating class in 1870 , completing her degree in two years. She applied to the Massachusetts Institute of Technology (MIT) in 1871. She was the first woman accepted to that or any other scientific institution, by special exemption from the MIT board, with a notation that it was "understood that her admission did not establish a precedent for the general admission of females."

Upon graduating from MIT in 1873, she appealed to the Women's Education Association of Boston for help in establishing a laboratory at MIT for the instruction of women in chemistry. The laboratory was opened in 1876 , with Richards serving in an assisting role and holding the position of instructor in chemistry and mineralogy. She was the only woman to teach at MIT during her lifetime. Richards is also widely credited with founding the field later known as ecology, and cofounded what would eventually become the Woods Hole Marine Biological Laboratory.

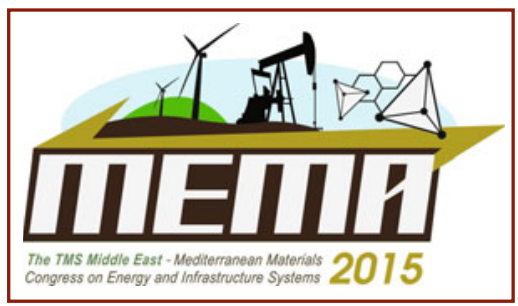

TMS Announces New Materials Congress on Energy and Infrastructure Systems

A new TMS meeting that builds on established materials partnerships between organizations in the United States and Qatar is set for January 11-14, 2015, in Doha, Qatar. The TMS Middle East - Mediterranean Materials Congress on Energy and Infrastructure Systems (MEMA 2015) will focus on materials research and development that is of particular interest in the Middle East and Mediterranean/North Africa region. A key goal of MEMA is to convene materials researchers and educators in that region, as well as the rest of the world, to encourage development of new collaborations. Topics to be covered include: sustainable infrastructure materials; materials for energy extraction, conversion, and storage; and computational materials design.

MEMA 2015's lead organizer is Ibrahim Karaman, Texas A\&M University. The National Science Foundation recently established the International Institute for Multifunctional Materials for Energy program at Texas A\&M and the Qatar Materials Science and Engineering Center at Qatar University. Check the TMS website regularly for news on abstract submission and other details related to this new opportunity.

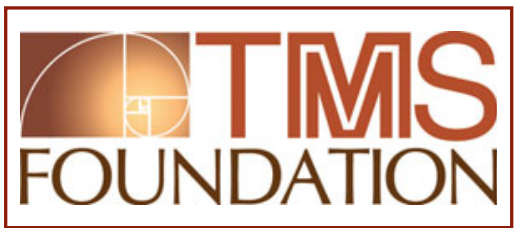

\section{Robert Wagoner Named} TMS Foundation Chair

The TMS Board of Directors has

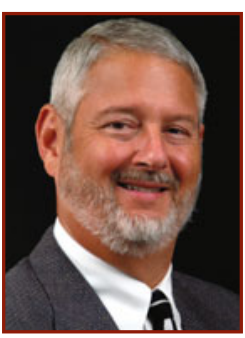
appointed Robert Wagoner, professor emeritus, Department of Materials Science and Engineering, The Ohio State University, and 1997 TMS President, as the new chair of the TMS Foundation. Wagoner brings an extensive history of volunteering with TMS, most recently as chair of the TMS Foundation Revitalization Board Committee that had been charged with exploring new avenues of growth and service for the Foundation. To build on this work, 
the TMS Board has expanded and restructured the TMS Foundation Board of Trustees and will be announcing a series of new Foundation activities and initiatives in the coming months. Look to future issues of JOM for details on these efforts. In the meantime, contributions to the Foundation are being accepted through its new website at www.TMSFoundation.org.

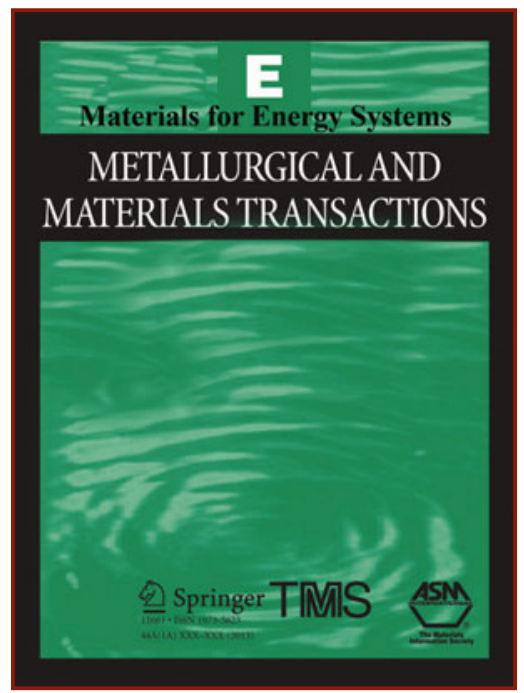

Metallurgical and Materials

\section{Transactions $E$ Seeks}

\section{Reviewers}

Metallurgical and Materials Transactions E: Materials for Energy Systems is seeking volunteers for the journal's roster of reviewers. Peer reviewers provide feedback to the key readers about the merits of submissions in terms of quality and contribution to the field and are expected to write reviews in a timely and constructive manner.

Officially launched by TMS and ASM International earlier this year, Metallurgical and Materials Transactions $E$ is set to debut in March 2014. Its content spans the science and technology of energy materials, from production and generation, to transmission, to energy storage and conversion. Establishing Metallurgical and Materials Transactions E as a scientific journal of the highest quality depends upon reviewers with a high level of expertise and an ability to be objective and insightful in their evaluation of manuscripts.
TMS members interested in serving in this critical role should submit a curriculum vitae and list of publications tomettrans@andrew.cmu.edu.

Metallurgical and Materials Transactions $E$ is accepting papers for publication in 2014 on the following topics:

- Batteries

- Biomass

- Fuel cell

- Geothermal

- Hydrocarbons

- Hydrogen storage

- Nuclear

- Solar cell

- Supercapacitor

- Thermal conversion

- Thermochemistry

- Thermoelectricity

- Wind

- Other energy systems that may emerge

Coverage may include a variety of areas of materials research, including larger materials issues with applications to energy. Articles may be submitted online at http://mmte.msubmit .net.

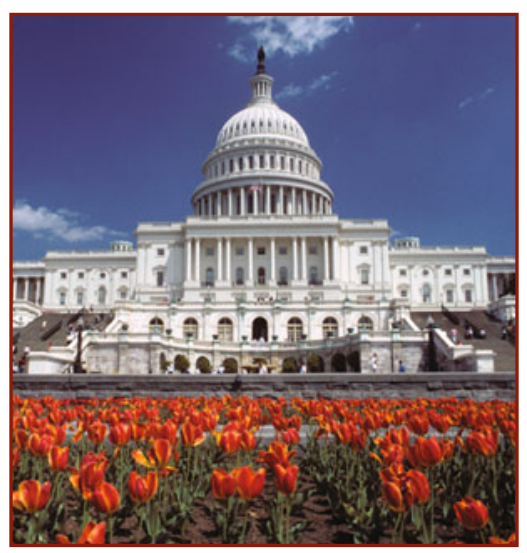

\section{Congressional Fellow Update}

Megan Brewster, the 2013-2014

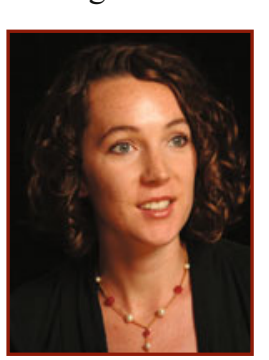

TMS/Materials Research Society (MRS) Congressional Science \& Engineering Fellow, has accepted placement with the majority Megan Brewster staff of the Sen- ate Committee on Energy and Natural Resources. She will focus on issues related to energy, including: renewable energy, energy efficiency, the energy-water nexus, critical minerals, advanced manufacturing, funding for energy-related research, and energy-related tax policy. On these topics, she will convene stakeholders, develop legislation, brief Committee Chairman Ron Wyden, draft communications and speeches, and attend committee hearings and business meetings.

Applications are being accepted through January 3, 2014, for the 2014-2015 TMS/MRS Congressional Fellowship. To be considered for the fellowship, applicants must have a record of success in research or scholarship in a field relevant to materials science, while also demonstrating a strong interest in applying scientific and technical knowledge to U.S. public policy issues. Additional critical qualities include the ability to work quickly and communicate effectively to both scientific and nonscientific audiences on a wide variety of topics, as well as being able to work cooperatively with individuals having diverse viewpoints. An applicant is expected to be a member or an applicant for membership of TMS or MRS, and must have a Ph.D. by September 1, 2014. U.S. citizenship is not required, but applicants must be authorized to work in the United States.

The American Association for the Advancement of Science Congressional Science and Engineering Fellows Program is operated as a cooperative effort of approximately 30 national scientific and engineering societies that provide an opportunity for accomplished scientists and engineers with public policy interests to learn about and contribute to the policy-making processes in Congress.

For additional information on the 2014-2015 TMS/MRS Congressional Science and Engineering Fellowship, contact Mary Samsa, TMS Foundation and Public Affairs Manager, atmsamsa@tms.org. 